\title{
Exhaled nitric oxide in specific challenge tests to assess occupational asthma
}

\author{
R. Piipari*, P. Piirilä*\#, H. Keskinen*, M. Tuppurainen*, A. Sovijärvi”, H. Nordman*
}

Exhaled nitric oxide in specific challenge tests to assess occupational asthma. R. Piipari, P. Piirilä, H. Keskinen, M. Tuppurainen, A. Sovijärvi, H. Nordman. (C) ERS Journals Ltd 2002.

ABSTRACT: Exhaled nitric oxide (NO) is a marker of esinophilic inflammation of the airway mucosa accompanying changes in the clinical condition of asthma. Allergen exposure has been associated with delayed elevation of exhaled NO. The aim of this study was to assess the asthmatic airway inflammation with exhaled NO measurements during specific bronchial challenge tests with occupational agents.

Forty patients with suspected occupational asthma were investigated. Specific bronchial challenge tests were performed with forced expiratory volume in one second or peak expiratory flow follow-up, supplemented by exhaled NO measurements before and $24 \mathrm{~h}$ after challenge tests.

In active challenges, which induced bronchoconstriction, a significant mean increase of exhaled NO concentration was noted. In patients with a normal or slightly increased ( $<$ 14.5 parts per billion (ppb)) basal NO level and a late bronchoconstriction, a significant increase in exhaled NO was seen. Patients with a high basal NO level $(>14.5 \mathrm{ppb})$ and a significant bronchoconstriction did not show a significant NO elevation. Challenge tests without bronchoconstriction were not associated with a significant elevation of exhaled NO.

Exhaled nitric oxide measurements can be used to indicate the development of airway inflammation accompanying late asthmatic reaction after bronchial challenge tests in patients with a normal or slightly increased basal nitric oxide concentration.

Eur Respir J 2002; 20: 1532-1537.
*Finnish Institute of Occupational Health, Dept of Occupational Medicine, and ${ }^{\#}$ Helsinki University Hospital, Laboratory of Clinical Physiology, Helsinki, Finland.

\section{Correspondence: R. Piipari}

Finnish Institute of Occupational Health Topeliuksenkatu 41 aA

FIN-00250 Helsinki

Finland

Fax: 35894584761

E-mail: Ritva.Piipari@occuphealth.fi

Keywords: Asthma

challenge tests

exhaled nitric oxide

occupational asthma

Received: May 212002

Accepted after revision: July 132002
Changes in the level of exhaled nitric oxide (eNO) reflect changes in the inflammatory status of the airways [1-3]. Increased levels of eNO have been observed in asthmatic patients, apparently produced by the inducible nitric oxide synthase (iNOS) as the result of induction by inflammatory mediators accompanying the asthmatic airway inflammation $[4,5]$. Biopsy studies have demonstrated an increased expression of iNOS in bronchial epithelial cells of asthmatics. After use of peroral or inhaled steroids the expression of iNOS is reduced parallel with decreasing eNO levels [6, 7]. eNO has been found to correlate with the number of eosinophils and the level of eosinophilic cationic protein in induced sputum, indicating that eNO specifically reflects eosinophilic inflammation [8-10]. After allergen challenges, elevated eNO levels have been reported at the time of the late response [11-13].

In the diagnostics of occupational asthma, the bronchial challenge test is the most reliable method of confirming the relationship between the causative agent and the asthmatic airway reaction. The asthmatic reaction is assessed by lung function measurements such as forced expiratory volume in one second (FEV1) or peak expiratory flow (PEF). These are not very sensitive indicators of obstruction and may be biased by patient cooperation.
The aim of this study was to assess the usefulness of eNO measurement as a marker of airway inflammation induced by bronchial challenge tests in patients with suspected occupational asthma.

\section{Patients and methods}

\section{Study subjects and design}

Altogether, 40 patients with suspected occupational asthma were investigated at the Finnish Institute of Occupational Health (Helsinki, Finland) between February 2000 and January 2001. Suspicion of occupational asthma was based on work-related asthma-like symptoms, specific immunoglobulin (Ig)E measurements (skin-prick tests or specific IgE measurements), lung function tests and PEF surveillance at work and at home. Bronchial challenge tests were carried out with the suspected occupational agents (active challenges) and a suitable control material (placebo challenges) in all patients. Airway obstruction was followed up by spirometric measurements (FEV1 and PEF) and airway inflammation was assessed by eNO measurements. For the duration of the challenge tests, patients stayed overnight at the patient ward. Patient characteristics are presented in table 1 . 
Table 1.- Patient characteristics

\begin{tabular}{lc}
\hline Patients n & 40 \\
Sex M:F & $17: 23$ \\
Age mean (range) & $42.3(20-59)$ \\
Smoking & 20 \\
$\quad$ Neversmokers n & 8 \\
Exsmokers ${ }^{\#}$ & $12(0.8-40.5)$ \\
Current smokers n (pack-yrs) & $25: 15$ \\
Atopy no:yes & $29: 10: 6$ \\
Specific IgE no:yes:not tested & $0.195(0.011-0.700)$ \\
B-eosinophil count $10^{9} \cdot \mathrm{L}^{-1}$ & $13: 27$ \\
mean (range) & $13: 27$ \\
Previous asthma diagnosis no:yes & $17: 23$ \\
Previous asthma medication no:yes & 8 of 23 \\
PEF surveillance at work done no:yes & 5 of 23 \\
Complies with OA & 10 of 23 \\
Does not comply with OA & \\
Different & $3.39(2.17-4.79)$ \\
Baseline FEV1 & $94(64-121)$ \\
L mean (range) & $11: 35$ \\
\% pred mean (range) & 19 of 35 \\
Histamine provocation test done no:yes & 16 of 35 \\
PD15FEV1 $\geqslant$ mg $^{+}$ & $48: 2^{\$}$ \\
PD15FEV1 >1.6 mg & \\
Protective medication during & \\
challenge no:yes & \\
Challenge test result & $36: 14$ \\
Bronchoconstriction no:yes & \\
\hline
\end{tabular}

M: male; F: female; Ig: immunoglobulin; OA: occupational asthma; FEV1: forced expiratory volume in one second; PD15FEV1: dose of inhaled histamine causing a $15 \%$ fall in FEV1. \#: stopped smoking at least 1 yr before the examination; ${ }^{\uparrow}$ : defined as one or more positive $(\geqslant 3 \mathrm{~mm})$ reactions in the standard skin-prick test series; ${ }^{+}:$[14]; ${ }^{\S}$ : patients 12 and 31 .

\section{Lung function measurements}

Flow-volume spirometry was performed with a pneumotachograph spirometer connected to a computer (Medikro 909; Medikro Ltd, Kuopio, Finland) and Finnish reference values were used [15]. A histamine provocation test was performed according to the method of SovIJÄRVI et al. [14] following FEV1 values with a mass flow sensor spirometer (Vmax 20c; Medith Oy, Helsinki, Finland). The dose of inhaled histamine aerosol causing a $15 \%$ fall in FEV1 was measured. The PEF recordings at work and at home were performed according to BURGE [16].

\section{Allergologic evaluation}

Skin-prick tests to common environmental allergens (ALK-Abello A/S, Copenhagen, Denmark) and a commercial latex extract (Stallergenes SA, Fresnes Cedex, France) were carried out using a standard technique [17]. In addition, skin-prick tests to the specific work-related compounds were performed according to the work history: prick tests to moulds were performed with the commercial skin-prick extracts (ALK-Abello SA Spain, Madrid, Spain); isocyanates and acid anhydrides were prick tested as human serum albumin conjugates [17] and prick tests to enzyme preparations were performed as described by VANHANEN et al. [18]. In all the skin-prick tests, histamine hydrochloride $\left(10 \mathrm{mg} \cdot \mathrm{mL}^{-1}\right)$ was used as the positive control. A person was defined as atopic if one or more of the common environmental allergen prick tests was positive (diameter $\geqslant 3 \mathrm{~mm}$ ) and the same cut-off point was used as indication of sensitisation to the work-related compounds. Total $\operatorname{IgE}$ and the specific IgE antibodies to the commercial allergens were determined with Pharmacia UniCAP 100 (Pharmacia, Stockholm, Sweden), and specific IgE antibodies to isocyanates and acid anhydrides with Phadebas RAST [19]. Specific $\mathrm{IgE}$ values $>0.35 \mathrm{kU} \cdot \mathrm{L}^{-1}$ were defined positive.

\section{Bronchial challenge test methods}

The challenge tests were carried out in an isolated challenge chamber $\left(6 \mathrm{~m}^{3}\right)$ according to international guidelines [20, 21]. All challenges were performed before noon, one test per day, lasting for 15-45 $\mathrm{min}$. The tests were designed individually, based on the patients' work history. The test agents of the active challenges are shown in table 2 .

Challenge tests with the isocyanates toluene diisocyanate, diphenylmethane diisocyanate and hexamethylene diisocyanate were performed as described previously [22].

Challenge tests with commercial allergen extracts (freeze-dried allergen extracts of Aspergillus fumigatus, Acremonium kiliense, cow epithelium (ALK Abello SA Spain)) were carried out by diluting the extract with the diluent (ALK solvent; ALK Abello SA Spain). The diluted allergen extracts were inhaled by an inspiratory synchronised dosimetric device (Spira Electro 2) with the following settings: driving pressure $0.2 \mathrm{kPa}$ ( 2 bars), inhalation time $0.8 \mathrm{~s}$, starting volume $50 \mathrm{~mL}$, inspiratory flow $0.5 \pm 0.1 \mathrm{~L} \cdot \mathrm{s}^{-1}$ and amount of allergen mixture $0.8-1.0 \mathrm{~mL}$. The starting allergen dilution was 1:10,000-1:1,000 weight/volume (w/v) depending on the severity of the patient's symptoms

Table 2. - Agents used in active challenge tests

\begin{tabular}{lc}
\hline Agent & Challenges $\mathrm{n}$ \\
\hline Aspergillus fumigatus & 19 \\
Acremonium kiliense & 3 \\
Isocyanates & 8 \\
Acid anhydrides & 3 \\
Wheat flour & 3 \\
Two-component paints & 2 \\
Enzymes & 2 \\
Acrylates & 1 \\
Chloramin-T & 1 \\
Colophony & 1 \\
Cow epithelium & 1 \\
Decorative plants & 1 \\
Epoxy resin & 1 \\
Latex & 1 \\
Persulphates & 1 \\
Stainless steel welding & 1 \\
Wood dust & 1 \\
Total & 50 \\
\hline
\end{tabular}


and the strength of sensitisation. The allergen dose was increased every $15 \mathrm{~min} 5$-10-fold if the patient had not reacted to the earlier dose, until the dilution of $1: 5 \mathrm{w} / \mathrm{v}$ was achieved.

The challenge test with a bacterial protease enzyme was performed by inhaling a mixture of the powderform protease preparation with lactose powder through a face mask from a prototype dust generator with the protease air concentration controlled.

In other challenges, the patients simulated their work tasks in the challenge chamber by handling an adjusted amount of the challenge material for 15-45 min. In the challenges to flours and wood dust, the dust was aired up by pressurised air. In the challenge tests to isocyanates and acid anhydrides, the air concentrations were controlled.

As negative placebo tests, the following materials were used: lactose powder for dusty agents; the corresponding diluent for allergen extracts (ALKDiluent; ALK Abello A/S); pressurised "Coca" solution $(0.5 \% \mathrm{NaCl}, 0.275 \%$ sodium bicarbonate, $0.4 \%$ phenol; Finnish University Pharmacy, Helsinki, Finland) or polyol (hydrogenated decene oligomers, Nexbase 200 6FG; Neste PAO NV, Beringen, Belgium) for mixtures in liquid form, isocyanates and soldering; a paint without hardener for two component paints; welding black iron for welding stainless steel; a weak $\mathrm{HCl}$ mixture, 1 part per million for chlorendic acid anhydride; latex-free examination gloves for latex gloves; and lettuce for decorative plants.

The patient's clinical status and lung function measurements were followed-up and controlled by a nurse for $24 \mathrm{~h}$ after each challenge. FEV1 and PEF values were measured with a pocket-sized spirometer (One Flow; STI Medical, St Romans, France) according to a protocol described previously [23]. PEF measurements were used as well as the more sensitive FEV1 measurements, because in the authors' experience there are patients in whom significant drops in PEF values are registered without concomitant drops in FEV1 values. A fall of $\geqslant 15 \%$ during the first hour after challenge was regarded as a significant immediate reaction. A drop of $\geqslant 20 \%$ occurring for over $1 \mathrm{~h}$ after the challenge was the criterion for a late reaction. If both reactions coexisted, the reaction was termed a dual reaction. If the immediate reaction lasted for $>1 \mathrm{~h}$ after the challenge, it was called an immediate prolonged reaction. As the patients were followed-up for $24 \mathrm{~h}$ by spirometric measurements, histamine provocation tests were not routinely carried out after challenges.

\section{Exhaled nitric oxide analysis}

eNO measurements were performed in the Laboratory of Clinical Physiology of Helsinki University Hospital (Helsinki, Finland). The measurements were done in the morning before the placebo and active challenge tests and on the next morning, $\sim 24 \mathrm{~h}$ after the first measurement. eNO was measured using a chemiluminescence analyser (Sievers 270B; Sievers, Boulder, CO, USA). Expiratory air flow and exhaled volume were measured in real time with a pneumotachograph. The measurement procedure has been thoroughly described previously [24]. At least three repeated measurements were made with a slow exhalation from total lung capacity for $>15 \mathrm{~s}$ and a mean exhalation flow of $0.09-0.12 \mathrm{~L} \cdot \mathrm{s}^{-1}$ using a flow resistance created by a resistor $\left(100 \mathrm{cmH}_{2} \mathrm{O}\right.$; Model \#100R; Hans Rudolph, Kansas City, USA) in order to close the soft palate. The mean value of three determinations, taken at the end of each expiration as a mean of $3 \mathrm{~s}$ plateau value, was recorded for the analysis. Values $<12.0$ parts per billion ( $\mathrm{ppb}$ ) were regarded as normal, those $12.0-14.4 \mathrm{ppb}$ as slightly increased, and values $\geqslant 14.5 \mathrm{ppb}$ as significantly increased [24]. Patients were asked not to smoke for $4 \mathrm{~h}$, not to drink caffeine-containing drinks for $2 \mathrm{~h}$ and not to eat a heavy meal just before NO measurements. Asthma medication, antihistamines and other medicines with possible effect on the bronchial response were stopped before eNO measurements as recommended before bronchoprovocation tests on the investigation of occupational asthma $[20,25]$.

\section{Statistical methods}

The NO values before and after the challenge tests were compared with a paired t-test. The NO values in the placebo tests and challenge tests with and without bronchoconstriction were studied separately. Active challenge tests followed by bronchoconstriction were further divided into those with a normal or slightly increased $(<14.5 \mathrm{ppb})$ and those with an elevated $(\geqslant 14.5 \mathrm{ppb})$ basal NO level for t-test comparison. Correlation tests were not applicable due to the great variation.

\section{Results}

Altogether, 40 patients were examined, on whom 42 placebo and 50 active challenge tests were performed. The change in FEV1 after the placebo challenge test was not significant in any of the patients. Of the 50 active challenge tests, 14 resulted in significant bronchoconstriction and 36 were negative. The bronchoconstriction was measured by FEV1 in 46 and by PEF in four cases. In the 14 tests with bronchoconstriction, the test reaction was immediate in three, immediate prolonged in three, dual in three and late in five cases. In the 42 placebo challenge tests performed, no significant change in eNO was observed.

When the active challenge tests were divided into groups according to the test result and basal NO level, different eNO profiles were observed (fig. 1 and table 3 ). The challenge tests without consequent bronchoconstriction did not show any significant change in eNO. All cases but one had a normal or slightly increased basal eNO level $(<14.5 \mathrm{ppb})$ which resulted in significant bronchoconstriction (reaction types: immediate prolonged in two, late in two and dual in three), a significant increase in eNO was noted. In all of these, the challenge test reaction included a 


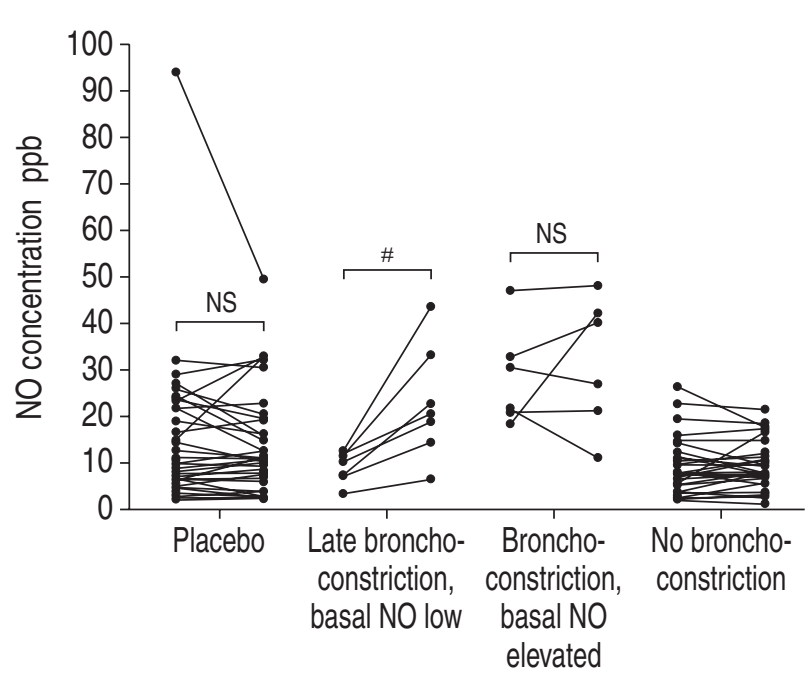

Fig. 1.-Exhaled nitric oxide (eNO) concentrations before and \# : $p=0.012$. late component. The only patient with a low basal NO level accompanied by bronchoconstriction but no significant NO elevation (patient 31), displayed an immediate reaction only and had specific IgE antibodies to the corresponding allergen (A. fumigatus). In cases with a high basal eNO (>14.5 ppb, six cases), the change in eNO after the challenge was not significant, despite significant bronchoconstriction (reaction types: immediate in two, immediate prolonged in one and late in three).

In table 4 the challenge test reaction types, basal NO concentrations, FEV1/PEF and the eNO responses of the challenge tests with bronchoconstriction are given.

\section{Discussion}

The present study indicates that eNO measurements can be used to detect the airway inflammatory reaction after specific challenge testing. Twenty-four hours after the challenge tests, the eNO concentration

Table 3. - Forced expiratory volume in one second (FEV 1 ) and exhaled nitric oxide (eNO) before and after the placebo and allergen challenge tests

\begin{tabular}{|c|c|c|c|c|c|c|}
\hline & \multirow[t]{2}{*}{ Subjects $n$} & \multicolumn{2}{|c|}{ FEV1 L } & \multicolumn{2}{|c|}{ eNO ppb } & \multirow[t]{2}{*}{ p-value ${ }^{\#}$} \\
\hline & & $\begin{array}{c}\text { Before } \\
\text { challenge test }\end{array}$ & $\begin{array}{c}\text { After } \\
\text { challenge test }\end{array}$ & $\begin{array}{c}\text { Before } \\
\text { challenge test }\end{array}$ & $\begin{array}{c}\text { After } \\
\text { challenge test }\end{array}$ & \\
\hline \multirow{5}{*}{$\begin{array}{l}\text { Placebo } \\
\text { Allergen challenge test } \\
\text {-bronchoconstriction } \\
\text { +bronchoconstriction } \\
\text { +late bronchoconstriction } \\
\text { +low basal NO level }\end{array}$} & 42 & $3.28 \pm 0.81$ & $3.03 \pm 0.62$ & $13.96 \pm 15.65$ & $12.64 \pm 10.70$ & 0.344 \\
\hline & & 3 & & & & 0.950 \\
\hline & $\begin{array}{l}36 \\
14\end{array}$ & $\begin{array}{l}3.23 \pm 0.77 \\
3.33+0.59\end{array}$ & $\begin{array}{l}2.94 \pm 0.67 \\
2.67+0.58\end{array}$ & $\begin{array}{c}8.44 \pm 5.89 \\
17.50+12.05\end{array}$ & $\begin{array}{c}8.40 \pm 5.04 \\
25.82+18.24\end{array}$ & 0.018 \\
\hline & 7 & $3.03 \pm 0.50$ & $2.43 \pm 0.44$ & $9.33 \pm 2.91$ & $20.41 \pm 11.67$ & \\
\hline & & & & & & 0.012 \\
\hline
\end{tabular}

Data are presented as mean \pm SD. ppb: parts per billion. ${ }^{*}$ : significance of eNO change after challenge test in paired t-test.

Table 4. - Challenge test reaction types, basal nitric oxide (NO) concentrations and forced expiratory volume in one second (FEV 1 )/peak expiratory flow (PEF) and NO changes after challenge with bronchoconstriction

\begin{tabular}{llcccc}
\hline Patient & Agent & $\begin{array}{c}\text { Reaction } \\
\text { type }\end{array}$ & $\begin{array}{c}\text { Basal } \\
\text { NO ppb }\end{array}$ & $\begin{array}{c}\text { FEV } / \text { PEF } \\
\text { change } \%{ }^{\#}\end{array}$ & $\begin{array}{c}\text { NO } \\
\text { change } \%\end{array}$ \\
\hline 1 & Chlorendic acid anhydride & IP & 10.33 & -30 & +83 \\
2 & Cyanoacrylate & L & 7.35 & -28 & +207 \\
3 & A. fumigatus & D & 12.37 & -21 & +66 \\
4 & A. fumigatus & L & 21.53 & -26 & -49 \\
12 & A. fumigatus & I & 46.83 & -20 & +2 \\
20 & A. kiliense & D & 7.13 & -21 & +102 \\
25 & A. fumigatus & IP & 11.50 & -19 (PEF) & +191 \\
26 & HHPA (heated) & IP & 18.40 & -22 (PEF) & +128 \\
30 & Wheat flour & I & 20.87 & -16 & +1 \\
31 & A. fumigatus & I & 10.77 & -18 & +16 \\
32 & Wheat flour & L & 30.40 & -27 & -12 \\
34 & Welding stainless steel & L & 32.57 & -21 (PEF) & +24 \\
37 & Epoxy paint+amine hardener & L & 3.27 & -31 & +102 \\
38 & Dimethylphthalate+polyester resin paint & D & 11.63 & -20 (PEF) & +275 \\
\hline
\end{tabular}

A. fumigatus: Aspergillus fumigatus; A. Kiliense: Acremonium kiliense; HHPA: hexahydro phtalic acid anhydride; I: immediate reaction, a fall of $\geqslant 15 \%$ during the first hour after challenge; IP: immediate prolonged reaction, a fall of $\geqslant 15 \%$ during the first hour after challenge and continuing for $>1 \mathrm{~h}$; L: late reaction, a fall of $\geqslant 20 \%$ for over $1 \mathrm{~h}$ after the challenge; D: dual reaction, combination of immediate and late reactions. "\#: the change in FEV1 and in PEF, when indicated. 
increased significantly in patients with a late bronchial reaction, if the basal level was normal or slightly increased $(<14.5 \mathrm{ppb})$. Patient 31 , with an isolated IgE-mediated immediate reaction, did not show a significant NO elevation. The NO concentration did not increase after active challenge tests without bronchoconstriction or placebo tests. In patients with a high (>14.5 ppb) basal NO level, the change in eNO after bronchoconstriction was not significant.

To the best of the authors' knowledge, there is no published data concerning NO analysis applied in the follow-up to bronchial challenge tests in the diagnostics of occupational asthma. The results presented here are consistent with earlier reports showing elevated eNO levels after allergen challenges at the time of the late response [11-13] and more pronounced changes in patients with a low in contrast to a high basal NO level [13].

During upper respiratory tract infections, eNO levels are increased [25]. According to the current authors' procedures, patients having had symptoms of respiratory tract infections within 3 weeks were not subjected to provocation tests. Therefore, it is unlikely that nonspecific postinfectious NO changes would have interfered with the results of this study. However, in cases when inhaled steroids have been used regularly, an increase in eNO after the challenge test might be caused by exacerbation of asthma due to withdrawal of the anti-inflammatory medication. According to the standard provocation procedures [26], inhaled steroids were withdrawn 3 days prior to challenge tests. In this study protocol, the standard protocol was strictly adhered to, as steroids may reduce the inflammatory response after challenges [2]. Steroids were withdrawn before the challenge tests in all but two patients, yet the asthma balance of all patients stayed stable prior to the tests according to spirometry and FEV1/PEF surveillances. Similarly, the eNO remained stable during placebo and negative active challenges, implying that withdrawal of the steroid was not the reason for the increase in NO after active challenges. In two patients, the challenge test was performed with the inhaled steroid on (patients 12 and 31). In one, the basal NO level was elevated despite steroid treatment $(46.83 \mathrm{ppb})$ whereas the other had a low basal NO level (10.77 ppb) and an isolated immediate reaction after challenge and no significant increase in eNO.

The maximum NO rise has been reported to occur between $10-21 \mathrm{~h}$ and a return to the basal level by $27 \mathrm{~h}$ after the challenge test $[11,12]$. For practical reasons, the NO measurements were only performed twice, at baseline and $24 \mathrm{~h}$ after each challenge. It is possible that NO levels would have been somewhat higher at an earlier time point.

The specific bronchial challenge test is the most reliable diagnostic test for occupational asthma. As a rule, the asthmatic reaction is followed up by functional parameters, i.e. FEV1 and/or PEF measurements, often supported by measurements of hyperreactivity [20, 21]. Neither the FEV1 nor PEF measurements are very sensitive and both are highly dependent on the patient's cooperation and expiration technique; difficulties in ensuring the quality of the measurements during the 24-h postchallenge follow-up are frequent. Clearly, NO measurements may help the interpretation of less clear-cut functional reactions. eNO objectively reflects the inflammatory response of the airways, which represents another aspect of the asthmatic reaction than the functional changes. A significant rise after the challenge test points to an inflammatory reaction induced by the challenge agent. The late asthmatic response is accompanied by an influx of inflammatory cells and release of inflammatory cytokines into the airways. It seems likely that the observed increase in NO production results from the induction of iNOS by these cytokines. However, in the presence of active inflammation, as in the patients with elevated basal NO levels despite functionally stable asthma, no additional iNOS induction seems to occur.

In this study, eNO increased significantly even in two cases in which the fall in PEF recordings was significant without a corresponding fall in FEV1 values (case 25: basal NO level $11.50 \mathrm{ppb}$, and case 26: basal NO level $18.49 \mathrm{ppb}$ ). There may be several reasons for false-negative and borderline pulmonary reactions in patients with occupational asthma. The 15-45-min provocation test does not necessarily correspond to an 8-h working day 5 days a week, the challenge agent and the causative agent at the workplace are probably not identical and the intensity of exposure may be too low to elicit a significant obstructive reaction. The demonstration of a clear inflammatory reaction in the bronchial mucous membranes following provocation should be of importance from a diagnostic as well as management point of view, particularly in cases with borderline or no functional reactions. As airway inflammatory changes precede the development of asthma, monitoring of airway inflammation provides a means to detect early stages of asthma, so called "asthma-like inflammation" [27]. Avoidance of further exposure and/or anti-inflammatory treatment at this stage may be important in preventing deterioration into clinical asthma.

Different sensitisers may require different levels of iNOS induction. In this study, several different exposure agents were used as challenge test material, but only few challenges were carried out with each agent. Therefore, from this study no conclusions about iNOS inducibility of different agents can be drawn.

In conclusion, the results presented here indicate that exhaled nitric oxide measurements can give useful additive information for the interpretation of occupational challenge tests in cases with borderline functional changes, increasing the validity of the tests. Exhaled nitric oxide measurement seems to be a promising complementary tool in the investigation, management and prevention of occupational and work-related asthma.

Acknowledgements. The authors would like to thank the staff of the patient ward of the Dept of Occupational Medicine at Finnish Institute of Occupational Health and the technicians of the Laboratory of Clinical 
Physiology in Helsinki University Hospital for their cooperation during the study, T.O. Piirilä for assistance in preparing the statistics and T. Kaustia for revising the text.

\section{References}

1. Alving $\mathrm{K}$, Weitzberg E, Lundberg JM. Increased amount of nitric oxide in exhaled air of asthmatics. Eur Respir J 1993; 6: 1368-1370.

2. Kharitonov SA, Yates D, Robbins RA, LoganSinclair R, Shinebourne EA, Barnes PJ. Increased nitric oxide in exhaled air of asthmatic patients. Lancet 1994; 343: 133-135.

3. Persson MG, Zetterström O, Agrenius V, Ihre E, Gustafsson LE. Single breath nitric oxide measurements in asthmatic patients and smokers. Lancet 1994; 343: $146-147$.

4. Robbins RA, Springall DR, Warren JB, et al. Inducible nitric oxide synthase is increased in murine lung epithelial cells by cytokine stimulation. Biochem Biophys Res Comm 1994; 198: 835-843.

5. Silkoff PE. Noninvasive measurement of airway inflammation using exhaled nitric oxide and induced sputum. Current status and future use. Clin Chest Med 2000; 21: 345-360.

6. Hamid Q, Springall DR, Riveros-Moreno V, et al. Induction of nitric oxide synthase in asthma. Lancet 1993; 342: 1510-1513.

7. Saleh D, Ernst P, Lim S, Barnes PJ, Giaid A. Increased formation of the potent oxidant peroxylnitrite in the airways of asthmatic patients is associated with induction of nitric oxide synthase: Effect of inhaled glucocorticoid. FASEB J 1998; 12: 929-937.

8. Obata H, Dittrick M, Chan H, Chan-Yeung $M$. Sputum eosinophils and exhaled nitric oxide during late asthmatic reaction in patients with western red cedar asthma. Eur Respir J 1999; 13: 489-495.

9. Chan-Yeung $M$, Obata $H$, Dittrick $M$, Chan $H$, Abboud R. Airway inflammation, exhaled nitric oxide, and severity of asthma in patients with western red cedar asthma. Am J Respir Crit Care Med 1999; 159: 1434-1438.

10. Silvestri M, Spallarossa D, Frangova Yourukova V, et al. A. Orally exhaled nitric oxide levels are related to the degree of blood eosinophilia in atopic children with mild-intermittent asthma. Eur Respir J 1999; 13: 321-326.

11. Kharitonov SA, O'Connor BJ, Evans DJ, Barnes PJ. Allergen-induced late asthmatic reactions are associated with elevation of exhaled nitric oxide. Am J Respir Crit Care Med 1995; 151: 1894-1899.

12. Paredi P, Leckie MJ, Horvath I, Allegra L, Kkharitonov SA, Barnes PJ. Changes in exhaled carbon monoxide and nitric oxide levels following allergen challenge in patients with asthma. Eur Respir $J$ 1999; 13: 48-52.

13. Thomassen MJ, Raychaudhuri B, Dweik RA, et al. Nitric oxide regulation of asthmatic airway inflammation with segmental allergen challenge. J Allergy Clin Immunol 1999; 104: 1174-1181.

14. Sovijärvi ARA, Malmberg LP, Reinikainen K, Rytilä P, Poppius H. A rapid dosimetric method with controlled tidal breathing for histamine challenge. Repeatability and distribution of bronchial reactivity in a clinical material. Chest 1993; 104: 164-170.

15. Viljanen AA. Reference values for spirometric, pulmonary diffusing capacity and body plethysmographic studies. Scand J Clin Invest 1982; 42: Suppl. 159, 1-50.

16. Burge BS. Single and serial measurements of lung function in the diagnosis of occupational asthma. Eur J Respir Dis 1982; 63: Suppl. 123. 47-59.

17. Kanerva L, Estlander T, Jolanki T. Skin testing for immediate hypersensitivity in occupational allergology. In: Menne T, Maibach HI, eds. Exogenous Dermatoses: Environmental Dermatitis. Boca Raton, CRC Press, 1991; pp. 103-126.

18. Vanhanen M, Tuomi T, Hokkanen H, et al. Enzyme exposure and enzyme sensitisation in the baking industry. Occup Environ Med 1996; 53: 670-676.

19. Keskinen H, Tupasela O, Tiikkainen U, Nordman H. Experiences of specific IgE in asthma due to diisocyanates. Clin Allergy 1988; 18: 597-604.

20. Cartier A, Bernstein IL, Burge PS, et al. Guidelines for bronchoprovocation on the investigation of occupational asthma. J Allergy Clin Immunol 1989; 84: 823829.

21. Allergy Practice Forum. Guidelines for the diagnosis of occupational asthma. Clin Exp Allergy 1992; 22: 103-108.

22. Piirilä PL, Nordman H, Keskinen HM, et al. Longterm follow-up of hexamethylene diisocyanate-, diphenylmethane diisocyanate-, and toluene diisocyanate-induced asthma. Am J Respir Crit Care Med 2000; 162: 516-522.

23. Keskinen H, Piirilä $\mathrm{P}$, Nordman $\mathrm{H}$, Nurminen M. Pocket-sized spirometer for monitoring bronchial challenge procedures. Clin Physiol 1996; 16: 633-643.

24. Ekroos H, Tuominen J, Sovijärvi ARA. Exhaled nitric oxide and its long-term variation in healthy nonsmoking subjects. Clin Physiol 2000; 20: 434 439.

25. Kharitonov SA, Yates D, Barnes PJ. Increased nitric oxide in exhaled air of normal human subjects with upper respiratory tract infections. Eur Respir J 1995; 8: 295-297.

26. Nordman H, Keskinen H. Keuhkojen ammattitaudit. In: Kinnula V, Laitinen LA, Tukiainen P, eds. Lung diseases (in Finnish). Duodecim, 1999; pp. 602-604.

27. Haahtela T. Early treatment of asthma. Allergy 1999; 54: Suppl. 49, 74-81. 